\title{
Smart Hybrid PABX Menggunakan Server Asterisk
}

\author{
Pembelanta Sinuhaji ${ }^{1}$, Heru Wijanarko ${ }^{2 *}$, Hamdani Arif ${ }^{3}$, dan Muchamad Fajri Amirul \\ Nasrullah $^{3}$

\begin{abstract}
${ }^{1}$ Program Studi Teknik Elektronika, Jurusan Teknik Elektro, Politeknik Negeri Batam,
${ }^{2}$ Program Studi Teknik Mekatronika, Jurusan Teknik Elektro, Politeknik Negeri Batam,
\end{abstract} \\ ${ }^{3}$ Program Studi Teknik Informatika, Jurusan Teknik Informatika, Politeknik Negeri Batam, \\ Batam, Indonesia
}

"Email: wijanarko@polibatam.ac.id

\begin{abstract}
Abstrak-Teknologi internet berkembang dengan pesat khususnya di bidang sistem informasi dan telekomunkasi. Pada dasarnya semua orang yang terhubung ke internet dapat bertukar informasi dan data. Untuk mendukung komunikasi agar berjalan dengan baik, penulis membutuhkan analog terminal adapter yang berfungsi untuk mengubah sinyal analog dari telepon dan mengubahnya kembali menjadi digital sehingga dapat ditransmisikan melalui internet. Dengan melakukan konfigurasi pada server Asterisk, penulis telah menghasilkan komunikasi antara IP-phone dengan IP-phone dan komunikasi antara telepon konvensional dengan IP-phone. Dengan memanfaatkan Private Automatic Branch Exchange (PABX) yang dikonfigurasi pada server Asterisk, maka telepon konvensional dapat terhubung dengan IP-Phone, sehingga sistem PABX secara hybrid dapat diimplementasikan.
\end{abstract}

Kata Kunci: PABX, Hybrid, Asterisk, Analog terminal adapter

\section{Pendahuluan}

KONDISI komunikasi antar ruangan di Politeknik Negeri Batam masih heterogen. Jalur utama menggunakan line telepon konvensional. Sedangkan beberapa tempat mulai diterapkan metode komunikasi menggunakan Voice over Internet Protocol (VoIP). VoIP sendiri adalah teknologi teknologi baru yang memungkinkan kita melakukan panggilan suara menggunakan IP jaringan [1].

Heterogenitas jalur komunikasi ini menimbulkan problem komunikasi. Interkoneksi antara dua teknologi yang berbeda masih menjadi kendala komunikasi untuk dua gedung berbeda. Solusi untuk menyelesaikan problem ini adalah dengan melakukan switching digital dan analog jalur komunikasi.

Smart Hybrid. PABX (Private Automatic Branch Exchange) adalah suatu model komunikasi yang dapat digunakan dalam pengaturan panggilan baik dari dalam jaringan maupun dari luar jaringan. Penerapan skema switching hybrid merupakan keunggulan yang telah digunakan dalam PABX ini [2]. PABX memungkinkan interkoneksi antara jalur telepon konvensional dengan VoIP. Selain itu alasan penggunakan PABX dalam implementasi ini adalah karena beberapa riset terkait yang telah melakukan improvement pada performansinya [3].

Posisi tengah dalam melakukan interkoneksi jaringan dengan PABX adalah pemanfaatan server Asterisk. Beberapa riset terkait [4] melakukan evaluasi performasi penggunaan Asterisk dalam hal kecocokannya untuk diimplementasikan pada layanan VoIP. Dari 160 panggilan secara bersamaan, hanya terjadi blocking kurang dari $5 \%$.

Berdasarkan penelitian-penelitian sebelumnya, penelitian ini secara umum berfokus pada implementasi PABX dan pemanfaatan server Asterisk.

\section{DASAR TEORI}

\section{A. IP-Phone}

Voice over Internet Protocol (VoIP) adalah teknologi komunikasi yang mampu melewatkan panggilan suara, video dan data melalui jaringan internet protocol (IP). Bentuk panggilan analog akan dikonversikan menjadi bentuk digital dan data akan dijalankan oleh internet protocol. Jaringan IP sendiri merupakan jaringan komunikasi data yang berbasis packed-switch, sehingga pengguna bisa menelepon dengan menggunakan jaringan internet protocol. Jaringan VoIP dapat dibangun dengan menggunakan jaringan nirkabel dan kabel. Prinsip kerja VoIP sendiri adalah untuk mengubah data suara analog yang didapatkan dari speaker pada komputer menjadi paket data digital, kemudian dari Personal Computer (PC) akan diteruskan melalui router dan dikirimkan melalui jaringan internet untuk kemudian diterima oleh tempat tujuan melalui media yang sama [5].

\section{B. Private Automatic Branch Exchange (PABX)}

PABX adalah suatu perangkat komunikasi yang digunakan untuk membuat beberapa percabangan ekstensi dalam satu atau lebih, di mana setiap ekstensi yang ada dapat saling berkomunikasi dengan penomoran yang telah ditentukan dan juga setiap ekstensi dapat diatur sesuai dengan keinginan 
admin. Pada sistem PABX digunakan telepon konvensional yang hanya dapat ditempatkan pada port PABX yang sudah ditentukan jumlah penomorannya. Selain itu, PABX juga memiliki fungsi sebagai pengatur panggilan masuk dan panggilan keluar [6].

\section{Asterisk}

Asterisk adalah perangkat lunak yang biasanya digunakan untuk membangun suatu sistem layanan komunikasi. Asterisk sendiri memberikan kemudahan kepada penggunanya untuk mengembangkan layanan telepon sendiri dengan jangkauan yang seluas-luasnya diberikan kepada pihak pengguna. Dari pengertian open source sendiri berarti setiap pengembang dapat melihat dan mengubah source code yang ada, sehingga aplikasi-aplikasi yang ada dapat ditambahkan dengan mudah oleh setiap pengembang. Asterisk juga dapat dikatakan sebagai PBX yang lengkap dalam bentuk software, karena Asterisk memiliki fungsi dan kemampuan layaknya PBX namun berbasis internet protocol. Kelebihan dari asterisk adalah dapat dioperasikan pada beberapa platform $O S$, antara lain Linux, Windows, BSD, dan OS X. Asterisk juga dapat terkoneksi dengan hampir semua standar yang berbasis telepon dengan menggunakan perangkat keras yang tidak begitu mahal sebagai gateway-nya [7].

\section{Analog terminal adapter}

Analog terminal adapter adalah perangkat komunikasi yang dapat digunakan untuk mengubah sinyal dari analog menjadi digital. Analog terminal adapter juga memungkinkan kita untuk menghubungkan pesawat telepon biasa ke komputer atau disambungkan ke internet untuk dipakai VoIP. Prinsip kerja Analog terminal adapter adalah mengubah sinyal analog dari telepon dan mengubahnya kembali menjadi data digital untuk ditransmisikan melalui internet. Bentuk fisik dari Analog terminal adapter dapat kita lihat pada Gambar 1 [8].

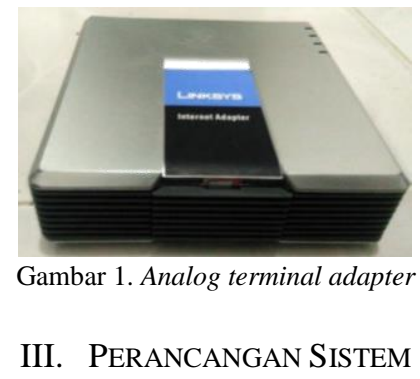

\section{A. Deskripsi Sistem}

Sistem yang dibuat dirancang dalam bentuk diagram alir yang dapat dilihat pada Gambar 2. Berdasarkan Gambar 2, apabila pengguna ingin melakukan komunikasi sesama telepon konvensional maka panggilan akan masuk ke PABX terlebih dahulu. PABX akan mengalihkan ke telepon konvensional yang ingin dituju. Begitu juga pada proses yang sama, di mana jika kita ingin berkomunikasi sesama IP-phone maka panggilan kita akan masuk ke jaringan vo-wifi dan melalui jaringan vo-wifi panggilan akan diteruskan ke $I P$ phone yang ingin kita tuju, dan bagaimana. Jika pengguna ingin berkomunikasi dari telepon konvensional ke $I P$ - phone, maka panggilan dari telepon kovensional akan menuju analog terminal adapter. Analog terminal adapter akan memberi kode ke telepon konvensional. Jika telepon konvensional ingin memanggil ke telepon konvensional, maka tekan tombol 1; dan jika pengguna ingin memanggil ke IP-phone maka tekan tombol 2. Begitu juga pada proses yang sama. Jika $I P$-phone ingin menghubungi atau memanggil ke telepon konvensional, maka server Asterisk akan menjadi jembatan penghubung antara telepon konvensional dengan $I P$ phone.

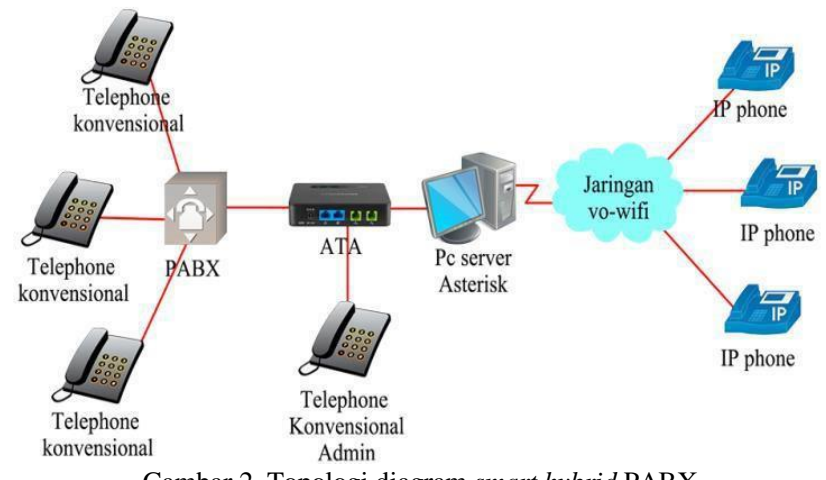

\section{B. Diagram Alir Sistem}

Pada sistem yang dibuat terdapat dua konsep yang berbeda, sesuai dengan dari mana akan dimulai panggilan. Jika ingin memulai panggilan melalui IP-Phone, maka dapat menggunakan diagram alir yang ditunjukkan pada Gambar 2. Jika dilakukan panggilan sesama IP-Phone, maka dapat menggunakan jaringan vo-wifi. Namun jika pengguna ingin melakukan panggilan ke telepon konvensional, maka harus melalui server sebagai penghubung.

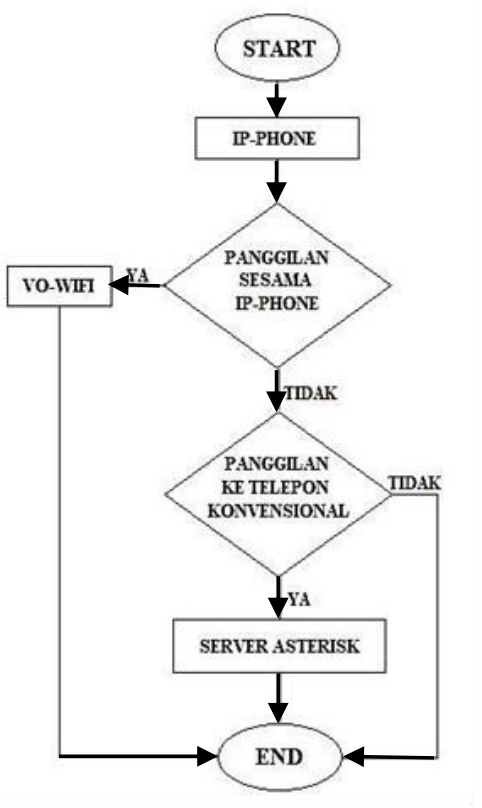

Gambar 2. Diagram alir sistem memulai panggilan dari IP-Phone

Jika pengguna ingin memulai panggilan dari telepon konvensional, proses dari sistem ditunjukkan oleh Gambar 3. 
Jika pengguna ingin memulai telepon melalui telepon konvensional dan ingin melakukan panggilan ke sesama telepon konvensional, maka dapat langsung menggunakan sistem PABX dari Polibatam. Tetapi jika pengguna ingin melakukan panggilan ke IP-Phone maka harus melalui server Asterisk sebagai penghubung.

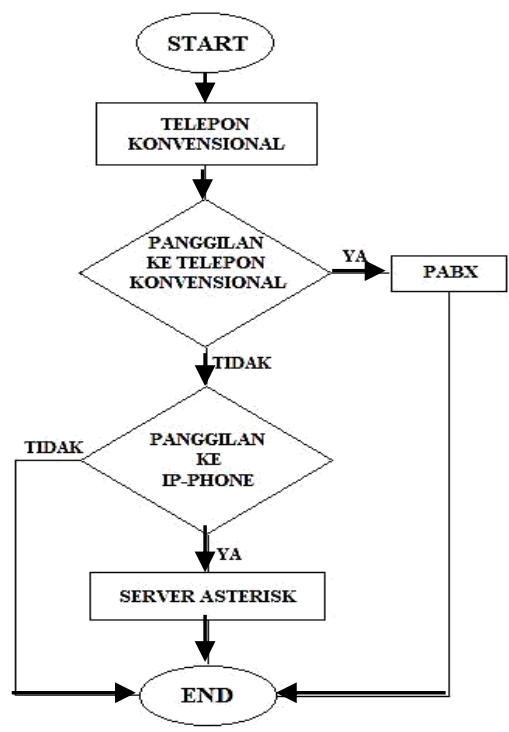

Gambar 3. Diagram alir sistem memulai panggilan dari telepon konvensional

\section{HASIL DAN ANALISIS}

\section{A. Pengujian}

Pada pengujian, sebagai representasi dari perancangan sisitem, disusun topologi jaringan dengan menggunakan IP private, seperti yang ditunjukkan oleh Gambar 4.

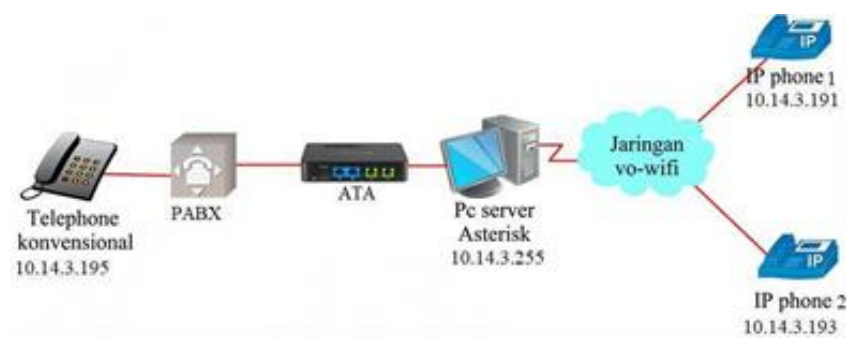

Gambar 4. Topologi jaringan sistem smart hybrid PABX

Berikut ini adalah percobaan ketika melakukan komunikasi antara IP-Phone dengan ekstensi 1111 dengan IP-Phone ekstensi 1112. Proses komunikasi diawali dengan mendaftarkan ekstensi 1111 dengan IP Address 10.14.3.191 menggunakan port 55345 dan ekstensi 1112 dengan IP Address 10.14.3.193 menggunakan port 51754. Proses komunikasi antara client 1 dan client 2 ditunjukkan tampilan pada server Asterisk pada Gambar 5.

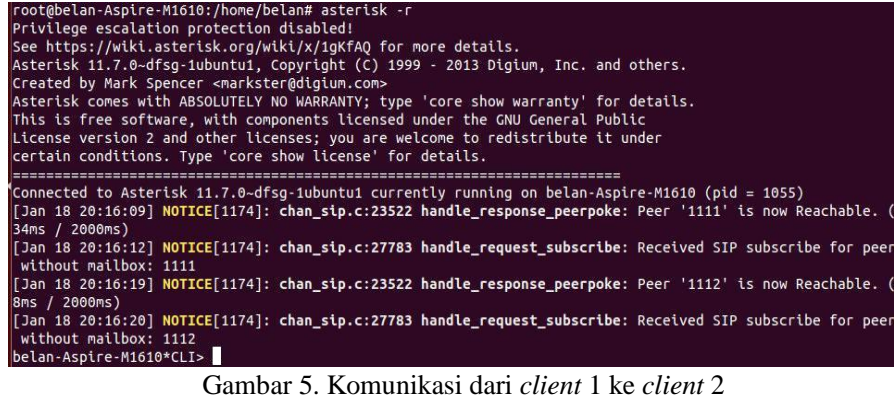

Untuk komunikasi sebaliknya (client 2 menghubungi client 1) dapat dilakukan dengan proses yang sama yaitu dengan memasukkan account name, User Id, domain (IP-address server asterisk), password, dan display name. Pada proses komunikasi ini, user id yang digunakan adalah 1112. Setelah berhasil, IP-Phone 1112 dapat memanggil IP-Phone 1111.

Percobaan selanjutnya adalah komunikasi dari IP-Phone ke telepon konvensional. Telepon konvensional didaftarkan sebagai nomor ekstensi 1113. Proses pendaftarannya yaitu dengan mendaftarkan telepon konvensional pada extension.conf dan SIP.conf di server Asterisk. Pada saat pengguna telah terdaftar pada server Asterisk dan dapat melakukan panggilan dari IP-Phone ke telepon konvensional, maka proses sebaliknya pun dapat dilakukan.

\section{B. Analisis}

Sistem yang dibangun menggunakan server Asterisk dapat melakukan komunikasi baik sesama IP-Phone, sesama telepon konvensional, maupun komunikasi dari IP-Phone ke telepon konvensional dan sebaliknya. Panggilan telepon tidak dapat terjangkau apabila nomor yang dituju tidak terdaftar pada server Asterisk. Error akan muncul pada saat user id yang digunakan tidak sesuai dengan apa yang didaftarkan, seperti yang ditunjukkan oleh Gambar 6. Pada kasus tersebut, error terjadi karena user id dan password tidak sesuai.

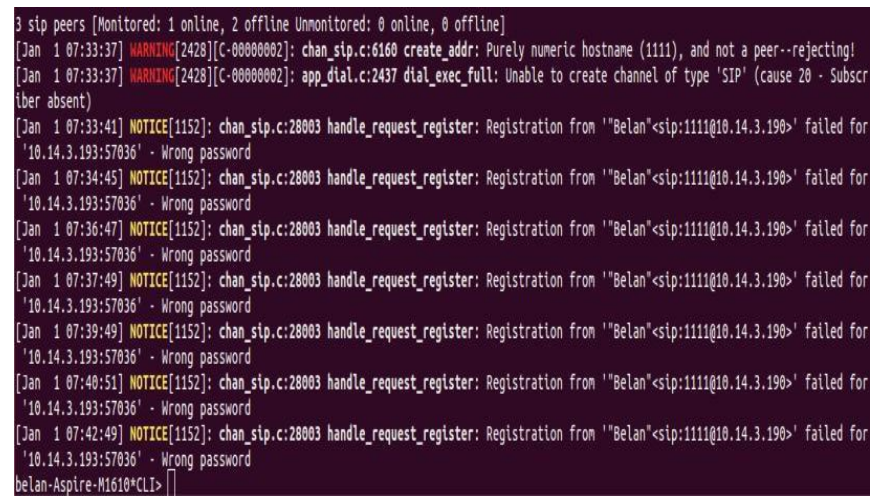

Gambar 6. Tampilan error pada server Asterisk saat user id dan password tidak match

Tampilan error lainnya adalah pesan rejected karena nomor ekstensi tidak dapat ditemukan pada konfigurasi extension.conf dan SIP.conf, seperti yang ditunjukkan pada Gambar 7. 


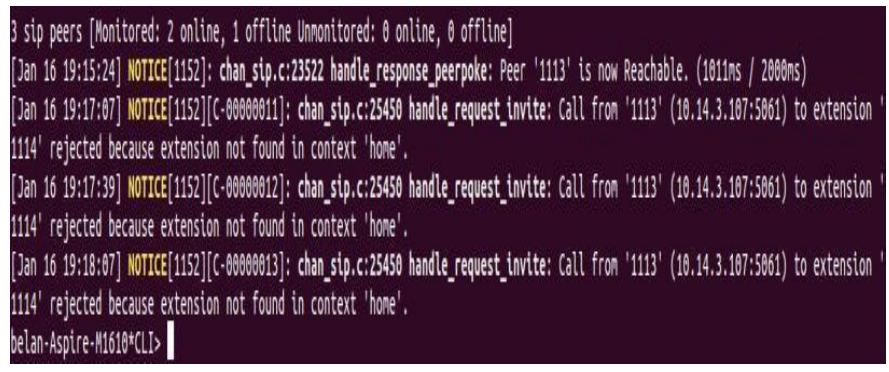

Gambar 7. Tampilan error pada server Asterisk dengan pesan rejected

\section{KESIMPULAN}

Setelah melakukan percobaan dan pengujian jaringan pada sistem yang dibuat, dapat diambil kesimpulan bahwa server Asterisk dapat digunakan untuk sebagai server VoIP baik untuk komunikasi sesama IP-Phone maupun komunikasi $I P$ Phone ke telepon konvensional. IP-Phone dan telepon konvensional dapat terhubung dengan server Asterisk apabila menggunakan ID dan domain name yang telah teregistrasi. Dengan memanfaatkan fitur pada Analog terminal adapter, telepon konvensional dapat memiliki IP Address sehingga dapat berkomunikasi pada jaringan VoIP.

\section{REFERENSI}

[1] Lu Tian et al., "Study of SIP protocol through VoIP solution of "Asterisk"," in Global Mobile Congress, Shanghai, China, December 2011.

[2] Shao-Ren Zheng, Zhao-De Guo, Shao-Hua Tang, and Tai-Yi Chen, "First integrated services PABX in China," in IEEE International Conference on Communications, World Prosperity Through Communications, Boston, 1989.

[3] Jing Liu, Jia Liu, Zuang Zhu, and Bo Xu, "A confidence based tree structured decoder for private automatic branch exchange," in WCC 2000 - ICSP 2000. 2000 5th International Conference on Signal Processing Proceedings. 16th World Computer Congress 2000, Beijing, China, 2000.

[4] Lucas Rodrigues Costa, Lucas Saad N. Nunes, Jacir Luiz Bordim, and Koji Nakano, "Asterisk PBX Capacity Evaluation," in 2015 IEEE International Parallel and Distributed Processing Symposium Workshop, Hyderabad, India, 2015.

[5] E. Prasetyo, "Impelmentasi VoIP (Voice over Internet Protocol) pada Jaringan LAN (Local Area Network) Dinas Kesehatan Kabupaten Musi Banyausin," Jurnal Teknik Informatika Politeknik Sekayu, vol. 2, no. 1, Februari 2015.

[6] A. Qustoniah and D. Siswanto, "Implementasi Teknologi VoIP (Voice over Internet Protocol) pada Jaringan PABX (Private Automatic Branch Exchange) di Lingkungan Universitas Widyagama Malang," Jurnal Dinamika Dotcom, vol. 6, no. 1, 2015.

[7] Cindy Meirissya, Asep Mulyana, and I Putu Yasa, "Analisis Layanan Video Conference pada Jaringan ADSL PT Telkom Bandung," Universitas Telkom, Bandung, Karya Ilmiah Skripsi S1 2008.

[8] Rindy, Viva Arifin, and Victor Amrizal, "Implementasi Internet Protocol Privat Branch Exchange dengan Menggunakan Session Intiation Protocol Sebagai Media Telekomunikasi : Studi Kasus PT. Transnetwork Communication Asia," UIN Syarif Hidayatullah Jakarta: Fakultas Sains dan Teknologi, Jakarta, Skripsi S1 2010. 